\title{
Illness Perceptions in Pediatric Spinal Muscular Atrophy: Agreement between Children and their Parents, and its Association with Quality of Life
}

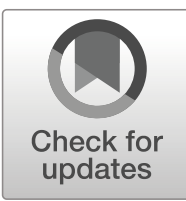

\author{
M. J. Fischer ${ }^{1}$ D $~ M$. Ketelaar $^{2}$ - P. J. van der Veere ${ }^{1} \cdot$ M. Verhoef $^{1}$. \\ R. I. Wadman ${ }^{3}$ - J. M. A. Visser-Meily ${ }^{1}$ - W. L. van der Pol ${ }^{3}$ - C. D. Schröder ${ }^{1,4}$
}

Published online: 17 June 2020

(C) The Author(s) 2020

\begin{abstract}
In adults with neuromuscular conditions illness perceptions show a strong relation with QoL. For young patients, illness perceptions are shaped through interaction with their parents. A shared perception between child and parent may benefit the child's QoL. This study investigated agreement in illness perceptions of children with Spinal Muscular Atrophy (SMA) and their parents, the association between the child's illness perceptions and QoL, and the relation between child-parent agreement in illness perceptions and the child's QoL. Twenty-six children and their parents completed the Brief Illness Perception Questionnaire (BIPQ) and the Kidscreen-52 QoL questionnaire (children only). Correspondence between children's and parents' illness perceptions was low. Generally, parents held more negative illness perceptions about SMA. Whereas children's illness perceptions were related to QoL, no clear association was found between agreement in illness perceptions and children's QoL. Therefore, to understand and improve QoL, healthcare professionals should discuss children's own illness perceptions during consultations.
\end{abstract}

Electronic supplementary material The online version of this article (https://doi.org/10.1007/s10882-02009749-7) contains supplementary material, which is available to authorized users.

\section{J. M. A. Visser-Meily}

Visser-Meilij@umcutrecht.nl

1 Department of Rehabilitation, Physical Therapy Science \& Sports, UMC Utrecht Brain Center, University Medical Center Utrecht, P.O. Box 85500, 3508GA Utrecht, The Netherlands

2 Center of Excellence for Rehabilitation Medicine, UMC Utrecht Brain Center, University Medical Center Utrecht, and De Hoogstraat Rehabilitation, Utrecht, the Netherlands

3 Department of Neurology, UMC Utrecht Brain Center, University Medical Center Utrecht, Utrecht, the Netherlands

4 Ecare4you, Amersfoort, the Netherlands 
Keywords Child-parentagreement · Common sense model Illness perceptions · Quality of life - Spinal muscular atrophy

Spinal muscular atrophy (SMA) is a rare degenerative neuromuscular disease with a recessive autosomal inheritance, typically diagnosed at young age (Kolb and Kissel 2015). Patients with SMA suffer from stalled motor development followed by slow decline of motor functions over the years, scoliosis, and problems with coughing, respiration and bulbar functions. Whereas traditionally SMA was treated symptomatically, newer therapies with SMN2 antisense oligonucleotides have been successful in slowing down disease progression, or even improving motor function (Finkel, Mercuri, Meyer, Simonds, Schroth, Graham et al. 2018). In spite of these promising advances, people with SMA are faced with many challenges as a result of their disease, which affect their Quality of Life (QoL). A nationwide study in the US comparing QoL of 125 children with SMA with that of healthy children found significantly lower scores among children with SMA regarding physical, psychosocial, emotional and school functioning (Iannaccone, Hynan, Morton, Buchanan, Limbers, Varni et al. 2009). Parents of these children also consistently rate the QoL of their children lower than parents of healthy children (Iannaccone et al. 2009).

Few studies have investigated predictors of QoL in patients with SMA. Mainly, the role of motor function and SMA subtype as a covariates of QoL have been investigated, with inconclusive results (de Oliveira and Araujo 2011; Iannaccone et al. 2009; Klug et al. 2016; Kruitwagen-Van Reenen et al. 2016). In order to preserve or improve QoL in this patient sample it is critical to identify contributing variables that are also amenable to intervention. Variables of particular interest in this regard are the individual's perceptions and emotions regarding the illness. According to Leventhal's Common Sense Model (CSM), the confrontation with a particular health threat, including a medical condition, will activate a person's illness perceptions. These perceptions are acquired lay theories that serve the individual to understand, adapt to, and manage the health threat or illness (Leventhal et al. 2003; Leventhal et al. 1980). These illness perceptions comprise several underlying dimensions including the physical symptoms that are associated with the illness, the consequences of the illness on the person's life, the controllability or curability of the illness, the expected timeline and the illness related concerns and emotions (Broadbent et al. 2006; Howard Leventhal et al. 1992). Many studies have shown that large proportions of variance in QoL can be explained by illness perceptions, even after the impact of disease severity variables has been taken into account (Broadbent et al. 2015; Hagger and Orbell 2003; Richardson et al. 2016b). With regard to neuromuscular diseases, a few studies have investigated the association between illness perceptions and QoL and found significant relations between patients' QoL and illness perception domains (Graham et al. 2013; Graham et al. 2014; Rose, Sadjadi, Weinman, Akhtar, Pandya, Kissel et al. 2012). These studies however have omitted patients with SMA, and have excluded respondents younger than 18 years. SMA differs from neuromuscular disorders that were included in previous studies (e.g. facioscapulohumeral muscular dystrophy, limb girdle muscular dystrophy) because of its typical early onset and its potentially life-threatening complications, especially for those diagnosed in early childhood.

Apart from personal experience with a particular illness, the CSM holds that patients' illness perceptions are shaped in interaction with significant others 
(Diefenbach and Leventhal 1996; Leventhal et al. 1998). For children with SMA living at home, parents are often their primary caregivers. As parents hold their own beliefs and emotions regarding SMA, these may serve as an important source of information for their children (Weinman et al. 2003). Research investigating correspondence between patients' and caregivers' illness perceptions has suggested that greater agreement in perceptions between both parties is associated with higher subjective wellbeing of patients, whereas dissimilarity in perceptions has been related to higher levels of patients' psychological distress and physical symptoms (Figueiras and Weinman 2003; Giannousi et al. 2016; Heijmans et al. 1999; Twiddy et al. 2012).

Understanding the association between children's illness perceptions and QoL in SMA holds potential for the development of psychosocial interventions. Therefore, this explorative study set out to investigate three related issues: 1) to what degree do children and their parents agree on their perceptions about SMA; 2) do children's illness perceptions show a meaningful pattern of associations with self-reported QoL domains; and 3) is the level of child-parent agreement in illness perceptions related to the child's QoL, after the child's own illness perceptions have been taken into account? Based on the intensive and long-lasting interaction between children with SMA and their parents-as-caregivers we expect that there will be considerable agreement between children's and parents' illness perceptions. Furthermore, we expect that more positive illness perceptions, and greater child-parent agreement in illness perceptions are associated with higher QoL.

\section{Methods}

\section{Procedure and Subjects}

Between December 2014 and October 2015, children with SMA and their parents who visited our clinic for standard care were invited for this study. Eligible respondents were children aged 8-18 diagnosed with SMA type 1-3, and their parents. They received written information about the study and, if they chose to participate, gave informed consent. All respondents received a questionnaire by mail with a prepaid return envelope. With a $63 \%$ response rate, 26 child-parent dyads were available for analysis.

\section{Questionnaires}

\section{Children's questionnaire}

The questionnaire for children opened with demographic questions about date of birth, sex and country of birth. Illness perceptions of children were assessed with the Brief Illness Perception Questionnaire (BIPQ) (Broadbent et al. 2006). This questionnaire has been validated for use in adults and children aged eight and older (Broadbent et al. 2015; Chong et al. 2012; Sonney et al. 2017). On a 0-10 scale, respondents were asked to rate eight different illness perception dimensions: Consequences ("How much does your illness affect your life?"), Timeline ("How long do you think your illness will continue?"), Personal control ("How much 
control do you feel you have over your illness?"), Treatment control ("How much do you think your treatment can help your illness?"), Identity ("How much do you experience symptoms from your illness?"), Concern ("How concerned are you about your illness?"), Illness comprehension ("How well do you feel you understand your illness?") and Emotional representation ("How much does your illness affect you emotionally?) to their disease. For the Consequences, Timeline, Concern, Identity and Emotional representation dimensions, higher scores indicate a more severe perception of disease. For the Personal control, Treatment control and Illness comprehensibility dimensions, a lower score indicates less control and less comprehension of the disease. For our study, the word "illness" was replaced with "SMA".

The Kidscreen-52 was used to assess QoL in children (Ravens-Sieberer et al. 2005). The Kidscreen-52 is divided into ten dimensions: Physical well-being, Psychological well-being, Mood and emotions, Self-perception, Autonomy, Parent relations and home life, Social support and peers, School environment, Social acceptance, and Financial resources. All questions are answered on a 5-point scale. Higher scores reflect better QoL. In a large European study, the Kidscreen-52 was shown to be reliable, valid and sensitive (Ravens-Sieberer et al. 2014). In the present study internal consistency for the Kidscreen-52 subscales was satisfactory, except for the Physical Well-being dimension for which Cronbach's alpha was very low $(\alpha=0,39)$. Consequently, this dimension has been excluded from further analyses.

\section{Parents' questionnaire}

Questionnaires for parents included demographic items (i.e. parents' age, sex, country of birth, education, income), followed by questions about their child (date of SMA diagnosis, living situation, education). Parents also completed an adapted version of the BIPQ. The questions were changed to reflect the way they view their child's disease (Szentes et al. 2018), for example: "How much does SMA affect the life of your child?" The domains Concern and Illness Comprehensibility in the parental questionnaire were formulated from the perspective of the parents themselves (i.e. parents' concerns and understanding of SMA), and therefore child-parent agreement was not calculated for these two dimensions.

\section{Statistical Methods}

Exploratory analyses were conducted to determine whether study variables followed a normal distribution. Skewness and kurtosis were investigated. Z-scores (kurtosis and skewness/standard error) $<|2|$ were considered acceptable. The Shapiro-Wilk test was performed to test the assumptions of normality. These tests showed that, with the exception of the Identity scale, Shapiro-Wilk test was significant for all BIPQ domains, indicating a non-normal distribution. In addition, visual and statistical analysis showed that the BIPQ Timeline and Emotional representations subscales were highly skewed. Therefore, non-parametric tests were used for the analyses.

Mean, standard deviation and median were calculated for BIPQ and Kidscreen-52 domains. Differences in parents' and children's illness perceptions were computed by subtracting children's BIPQ scores from parents' BIPQ scores. The Wilcoxon signed rank test was used to test if parents' and children's illness perceptions deviated significantly. 
Agreement between parents' and children's illness perceptions was expressed as a proportion of parent child dyads with exact agreement, and as proportion of dyads with a maximum of \pm 1 point difference in their BIPQ scores. Linear weighted kappa's for ordinal data were calculated to examine the level of agreement between parent and child for each BIPQ domain (Vanbelle 2016). Finally, Bland-Altman plots were produced to display the difference between child-parent illness perceptions against the child-parent mean score (Bland and Altman 1999). Mean difference and 95\% limits of agreement provide an indication of systematic bias and variability around mean differences.

The strength of the association between the child's illness perceptions scores and domains of their QoL was analysed with Spearman correlations. To determine if the level of child-parent agreement in illness perceptions is associated with the child's QoL, a non-parametric partial correlation was calculated between the absolute difference in BIPQ scores of the parent and child and the Kidscreen-52 score, controlled for the child's BIPQ score. For all tests $p<0,05$ was considered statistically significant. Analyses were done using SPSS version 24.0 software.

\section{Results}

Characteristics of children and their parents are summarized in Table 1. Almost $70 \%$ of respondents were diagnosed with SMA Type 2. Among the children, the majority were boys, whereas the majority of parents were mothers.

Regarding illness perceptions, children on average reported very high scores for the Timeline dimension (Table 2). This perception of a permanent disease parallels the relatively low perceived Personal and Treatment control. Lowest scores were found for the Emotional Representations domain. The perception of a long duration and poor controllability of SMA was shared between children and parents.

Comparing illness perceptions of children and parents, analyses showed that in general parents' BIPQ scores were higher than their children's scores, with the exception of the Treatment Control subscale (Table 2). The Wilcoxon test showed that for the domains of Illness Identity and Emotional Representations this difference was significant $(p=.01$ and $p=.03$, respectively), indicating that, compared with their children, parents thought SMA to have a greater impact on their child's physical and emotional functioning.

The proportion of child-parent dyads showing exact agreement on the BIPQ scores was low, with the exception of the Timeline dimension for which the majority $(>85 \%)$ of respondents answered that SMA would last an entire life (10 on a 10-point scale). Although exact agreement for the Emotional Representation dimension was low, absolute difference between parent and child scores fell within one point in $62 \%$ of dyads (Table 2). In support of this finding, weighted Kappa values show that agreement between parent and child was moderate for the BIPQ Emotional Representation dimension (.42), whereas it was poor for the other five dimensions.

Bland-Altman plots showed no systematic relationship between the difference scores and the child-parent mean scores on the BIPQ domains, indicating that the level of agreement between parent and child does not vary as a function of the perceived severity of the illness (See Supplementary Figures 1-6). 
Table 1 Participant characteristics

\begin{tabular}{ll}
\hline & $\mathrm{N}(\%)$ \\
\hline $\begin{array}{l}\text { Children }(N=26) \\
\text { Type SMA } \\
1\end{array}$ & \\
2 & $1(4 \%)$ \\
3 & $18(69 \%)$ \\
Age, M (SD) - Mdn & $7(27 \%)$ \\
Boys & $12.8(2.9)-13.0$ \\
Type of education & $16(62 \%)$ \\
Regular & \\
Special & $19(73 \%)$ \\
Other & $6(23 \%)$ \\
Parents $(N=26)$ & $1(4 \%)$ \\
Age, M (SD) - Mdn & \\
Mothers & $44.3(5.6)-45.0$ \\
Education & $20(77 \%)$ \\
Secondary & \\
Tertiary & $3(12 \%)$ \\
Other & $21(81 \%)$ \\
\hline
\end{tabular}

Values represent frequencies and percentages, unless stated otherwise

With regard to the association between children's illness perceptions and QoL, the Kidscreen-52 dimensions showed a consistent relation with the children's BIPQ subscales Consequences, Identity and Emotional Representation (Table 3). By contrast, the Timeline and Control dimensions were generally unrelated to the QoL subscales. Contrary to our expectations, all correlations between the BIPQ Treatment Control scale and the dimensions of QOL were negative, although only one of these associations reached statistical significance.

Finally, partial correlations between the difference in parent-child illness perceptions and the child's QoL scores on the whole were of lower strength than the zero-order associations between the child's illness perceptions and QoL (Table 4). Furthermore, the direction of the partial correlations varied, with negative and positive associations being spread across the correlation matrix in approximately equal numbers. This makes the relation between parent-child agreement in illness perceptions and the child's QoL difficult to interpret.

\section{Discussion}

Previous studies have demonstrated that spinal muscular atrophy negatively affects subjective well-being of children with SMA and their parents (Cremers et al. 2019; Iannaccone et al. 2009), and suggested that well-being is strongly related to personal cognitions and emotions regarding the disease (Hagger et al. 2017). With parents 


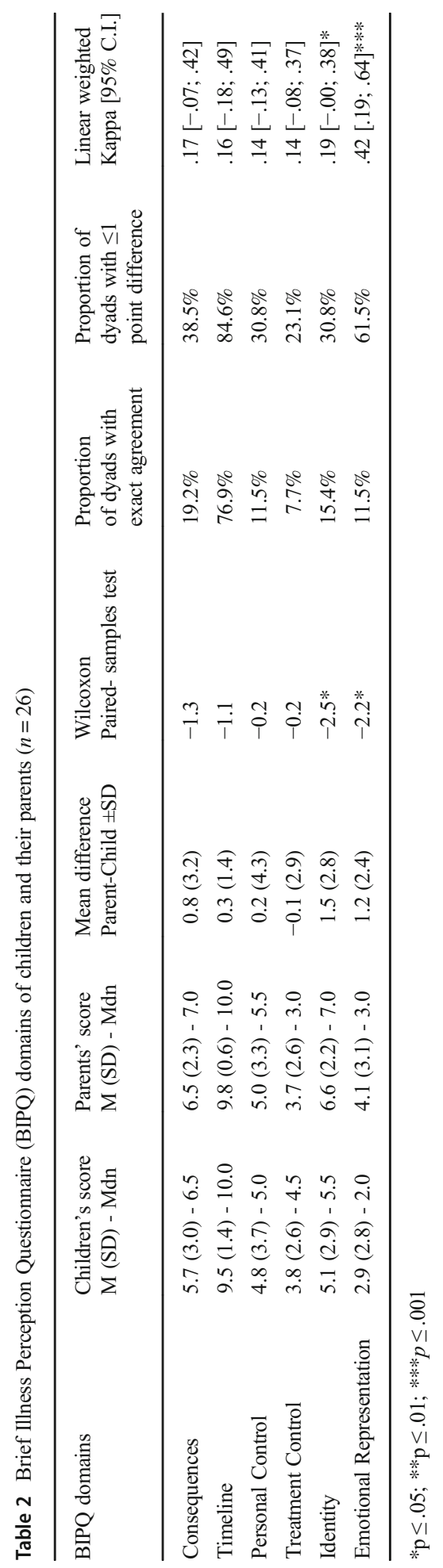


serving as primary caregivers of children with SMA, it is relevant to investigate to what degree children's and parents' illness perceptions are in agreement, and to explore how the level of child-parent agreement is related to children's well-being. Results from our study showed that the agreement between parents and children regarding the illness perceptions was weak and that parents often perceived the severity of SMA as greater than their children did. The children's own illness perceptions were strongly related to various domains of QoL, with more pessimistic views being associated with lower QoL scores. However, greater child-parent agreement in illness perceptions showed both positive and negative correlations with the child's QoL, which makes this relationship difficult to interpret.

This is the first study that compared illness perceptions of children with SMA and their parents. Our study suggested that parents in general had more negative illness perceptions about SMA than their children, especially with regard to the physical symptoms and the emotional impact of the disease. These more pessimistic views of parents on the disease of their children have also been observed in recent studies among parents and their children diagnosed with cancer, diabetes and asthma (Sonney et al. 2017; Szentes et al. 2018). This greater perceived severity is not exclusively present in parent-caregivers but has also been found in partner-caregivers of adult patients (Giannousi et al. 2016; Karademas et al. 2010; Richardson et al. 2015; Richardson et al. 2016a; Twiddy et al. 2012), making it less likely that immature intellectual abilities and limited understanding of the disease of the child are exclusively responsible for this discrepancy.

In addition to the more pessimistic perceptions by parents, illness perceptions of children and their parents appear to be relatively independent. According to the Common Sense Model illness perceptions are partly formed through social interaction and hence considerable correspondence between parents' and children's illness perception scores was expected. However, for most domains of the BIPQ the weighted

Table 3 Spearman correlations between children's BIPQ scores and Kidscreen-52 scores. $(n=26)$

\begin{tabular}{|c|c|c|c|c|c|c|}
\hline \multirow[t]{2}{*}{ Kidscreen-52 dimensions } & \multicolumn{6}{|l|}{ BIPQ domains } \\
\hline & Consequences & Timeline & $\begin{array}{l}\text { Personal } \\
\text { control }\end{array}$ & $\begin{array}{l}\text { Treatment } \\
\text { control }\end{array}$ & Identity & $\begin{array}{l}\text { Emotional } \\
\text { represent. }\end{array}$ \\
\hline $\begin{array}{l}\text { Psychological } \\
\text { well-being/life }\end{array}$ & $-.60 * * *$ & -.18 & .22 & -.27 & $-.63 * * *$ & $-.58 * *$ \\
\hline Moods and Emotions & $-.47 *$ & .22 & .15 & -.26 & $-.51 * *$ & $-.76^{* * *}$ \\
\hline Self-perception & $-.50^{* *}$ & .20 & .22 & $-.45^{*}$ & -.39 & $-.41 *$ \\
\hline Autonomy \& leisure & $-.43 *$ & .24 & -.10 & -.25 & -.26 & $-.40 *$ \\
\hline $\begin{array}{l}\text { Parent relations } \\
\qquad \& \text { home life }\end{array}$ & -.32 & -.16 & .17 & -.24 & -.19 & -.23 \\
\hline Social support \& peers & $-.50^{* *}$ & -.15 & .20 & -.07 & $-.45^{*}$ & $-.57 * *$ \\
\hline School environment & -.27 & -.26 & -.13 & -.09 & -.24 & -.22 \\
\hline Social acceptance & -.27 & .25 & .02 & -.10 & -.16 & -.37 \\
\hline Financial resources & $-.67 * * *$ & .20 & .22 & -.36 & $-.61 * * *$ & $-.61 * * *$ \\
\hline
\end{tabular}

$* \mathrm{p} \leq .05 ; * * \mathrm{p} \leq .01 ; * * * \mathrm{p} \leq .001$ 
Table 4 Partial correlation (Spearman) between the absolute difference of parents' and their children's BIPQ scores and children's Kidscreen-52 scores, controlled for the child's BIPQ score. $(n=26)$

\begin{tabular}{lllllll}
\hline Kidscreen-52 dimensions & \multicolumn{2}{l}{ BIPQ domains } & & & \\
\cline { 2 - 7 } & Consequences & Timeline & $\begin{array}{l}\text { Personal } \\
\text { control }\end{array}$ & $\begin{array}{l}\text { Treatment } \\
\text { control }\end{array}$ & Identity & $\begin{array}{l}\text { Emotional } \\
\text { represent. }\end{array}$ \\
\hline $\begin{array}{l}\text { Psychological } \\
\quad \text { well-being/life }\end{array}$ & .33 & $-.44^{*}$ & -.03 & .18 & -.06 & -.23 \\
Moods and Emotions & .39 & -.15 & .17 & .20 & -.12 & -.24 \\
Self-perception & -.07 & .03 & .21 & .11 & .31 & -.01 \\
Autonomy \& leisure & $.45^{*}$ & -.34 & .26 & $.42^{*}$ & .03 & -.15 \\
Parent relations & -.02 & -.33 & .20 & .18 & .13 & -.01 \\
$\quad$ \& home life & $.40^{*}$ & -.38 & .25 & .29 & .00 & -.17 \\
Social support \& peers & .28 & -.06 & .10 & .19 & .16 & .20 \\
School environment & .10 & -.16 & .29 & .24 & -.11 & .02 \\
Social acceptance & .23 & $-.40^{*}$ & .22 & .12 & -.17 & -.21 \\
Financial resources & & & & & & \\
\hline
\end{tabular}

$* p \leq .05$

kappa values were low and non-significant, with the exception of the Identity and Emotional Representation scales. A possible explanation for these results is that children's illness perceptions may be predominantly formed by their personal experience with their disease, whereas parents' perspective is influenced by observation and interpretation of their child's behaviour (Sonney et al. 2017; Sonney et al. 2016). Physical symptoms and emotional expressions may be more visible for a parent than their child's cognitive responses (e.g. perceptions about illness controllability and consequences). In similar fashion, higher child-parent agreement has been found for more observable QOL dimensions, such as physical well-being (Rajmil et al. 2013). The systematic overestimation by parents may point to the fact that once their child shows physical or emotional symptoms (e.g. fatigue, irritability or listlessness), parents generally attribute these signs to SMA, whereas the child may attribute them to a wide range of causes. For instance symptoms of fatigue, irritability or listlessness may be caused by SMA, just as they may arise from events experienced at school, in interaction with peers or after a lost game of wheelchair sports.

The second aim of this study was to investigate the association between the child's illness perceptions and his or her quality of life. In this study we found high associations between children's QoL and their perceptions of illness consequences, severity of symptoms and emotional representations. Whereas previous studies in the field of neuromuscular disorders had not included children or patients with SMA, many similarities were observed between outcomes of the present study and previous studies that investigated the relation between illness perceptions and QoL (Graham et al. 2014; Rose et al. 2012). Similarly, although very few studies have focused on illness perceptions in children, the associations observed in our study sample are not unique, as they have also been reported in studies among children with a variety of diagnoses, including cerebral palsy (Chong et al. 2012), asthma (Ringlever et al. 2012) and epilepsy (Rizou et al. 2015, 2016). Review studies give further support to the 
impression that the illness perception domains Consequences, Identity and Emotional representations are most closely related to patients' QoL and well-being (Broadbent et al. 2015; Hagger et al. 2017).

Living and growing up with SMA occurs in a social context and affects all individuals within a family. Illness perceptions of children with SMA and their parents affect their disease management, and it has been suggested that having a shared illness representation between parents and children may improve the quality of disease management and disease outcomes such as QoL (Sonney and Insel 2016). However, in contrast with others studies among patients and caregivers (Figueiras and Weinman 2003; Giannousi et al. 2016; Heijmans et al. 1999; Twiddy et al. 2012), we found no clear benefit for children's QoL when there was greater correspondence between children's and parents' illness perceptions. Whereas other studies compared perceptions of adult patients and their (spouse) caregivers, the present investigation included children and their parents, which may partly explain the difference in results.

\section{Limitations}

Illness perceptions of children with SMA have not been investigated previously. The absence of similar studies for comparison, the modest sample size and cross-sectional study design limit the interpretation and generalizability of our findings. Additionally, some limitations must be mentioned with regard to the instruments in this study. First, the physical well-being subscale of the Kidscreen-52 QoL questionnaire was left out of the analyses because of poor internal consistency. Further inspection of this scale reveals that it consists of items referring to the sense of feeling healthy, being physically active (including running), and feeling energetic. These three domains are likely to be unrelated for children in a wheelchair. While they may consider themselves healthy or energetic, most children with SMA are unable to run and their level of physical activity is low, causing the weak interrelations between the items in this scale. Secondly, the Concerns and Coherence subscales of the BIPQ were unable for comparison between children and parents because parental reports for these domains reflected the parents' own concerns and understanding of the illness.

\section{Implications for Research and Clinical Practice}

This exploratory study has shed new light on children's and parents' perceptions of SMA and the relationship between these perceptions and children's QoL. To increase generalizability of these findings, follow-up studies with larger samples are called for. As SMA is a rare disease, international collaboration is necessary to combine small subsets of patients from different countries. The BIPQ is available in more than 20 languages and may be suitable for this purpose. However, with regard to measuring QoL in children with neuromuscular disorders such as SMA, the KIDSCREEN-52 may be less appropriate. While it is widely used to assess QoL of youth from various countries, it is a lengthy questionnaire which makes it burdensome to complete for patients with poor hand and finger functions. Many of the SMA patients in our study were able to use their hands and fingers to operate a laptop or smartphone, and very few 
use eye control hard/software. However, muscle fatigability makes it tiresome to complete lengthy questionnaires. In retrospect, we feel that shorter questionnaires would have been more suitable for this study. Additionally, reliability of the physical well-being scale may be suboptimal for individuals with poor motor functions. Therefore, questionnaires designed specifically for this population such as the PedsQL neuromuscular module (Iannaccone et al. 2009) may be a valuable alternative. A final research implication pertains to the inclusion of parents. The majority (77\%) of parents in this study were mothers. Administering the BIPQ to fathers and mothers within the same family allows for a more elaborate investigation of child-parent agreement in illness perceptions. Furthermore, including both parents in the study may reveal to what extent parents agree with regard to their illness perceptions, and how parents' level of (dis)agreement affects the child's well-being.

With regard to the clinical implications, this study suggests that parents' views on SMA cannot be considered as a reliable proxy report, and children should be asked about their own views about their illness. As Sonney and colleagues have previously suggested (Sonney et al. 2017), school-aged children spend increasing amounts of time away from their parents and other sources of information (e.g. peers, teachers, school nurses and therapists) may influence the development of the child's illness perceptions. With their impaired motor functions, children with SMA are very dependent on their parents. However, in clinical consultations, healthcare providers should assess the perspective of parents and children separately. Emphasizing the contribution of the child in history taking and decision making may enhance their need of control and autonomy, which has been shown to relate to higher mental well-being in patients with SMA (Fischer et al. 2019).

\section{Conclusion}

In summary, this explorative study showed that there is low correspondence between children's and parent's views about SMA, and parents often perceive the severity of SMA as higher than their children. In light of the strong association of children's illness perceptions with their QoL clinicians should openly assess, discuss and if necessary modify the child's perceptions.

\section{Compliance with Ethical Standards}

Conflict of Interest The authors declare that they have no conflict of interest.

Ethical Approval All procedures performed in this study were in accordance with ethical standards of the institutional research committee and with the 1964 Helsinki declaration and its later amendments or comparable ethical standards. This protocol for this study was reviewed and approved by the hospital medical ethics committee.

Informed Consent All participating children and their parents gave written informed consent. 
Open Access This article is licensed under a Creative Commons Attribution 4.0 International License, which permits use, sharing, adaptation, distribution and reproduction in any medium or format, as long as you give appropriate credit to the original author(s) and the source, provide a link to the Creative Commons licence, and indicate if changes were made. The images or other third party material in this article are included in the article's Creative Commons licence, unless indicated otherwise in a credit line to the material. If material is not included in the article's Creative Commons licence and your intended use is not permitted by statutory regulation or exceeds the permitted use, you will need to obtain permission directly from the copyright holder. To view a copy of this licence, visit http://creativecommons.org/licenses/by/4.0/.

\section{References}

Bland, J. M., \& Altman, D. G. (1999). Measuring agreement in method comparison studies. Statistical Methods in Medical Research, 8(2), 135-160. https://doi.org/10.1177/096228029900800204.

Broadbent, E., Petrie, K. J., Main, J., \& Weinman, J. (2006). The brief illness perception questionnaire. Journal of Psychosomatic Research, 60(6), 631-637.

Broadbent, E., Wilkes, C., Koschwanez, H., Weinman, J., Norton, S., \& Petrie, K. J. (2015). A systematic review and meta-analysis of the brief illness perception questionnaire. Psychology \& Health, 30(11), 1361-1385. https://doi.org/10.1080/08870446.2015.1070851.

Chong, J., Mackey, A. H., Broadbent, E., \& Stott, N. S. (2012). Children's perceptions of their cerebral palsy and their impact on life satisfaction. Disability and Rehabilitation, 34(24), 2053-2060. https://doi. org/10.3109/09638288.2012.669021.

Cremers, C. H., Fischer, M. J., Kruitwagen-van Reenen, E. T., Wadman, R. I., Vervoordeldonk, J. J., Verhoef, M., Visser-Meily, J. M., van der Pol, W. L., \& Schröder, C. D. (2019). Participation and mental wellbeing of mothers of home-living patients with spinal muscular atrophy. Neuromuscular Disorders, 29(4), 321-329. https://doi.org/10.1016/j.nmd.2019.02.011.

de Oliveira, C. M., \& Araujo, A. P. D. C. (2011). Self-reported quality of life has no correlation with functional status in children and adolescents with spinal muscular atrophy. European Journal of Paediatric Neurology, 15(1), 36-39. https://doi.org/10.1016/j.ejpn.2010.07.003.

Diefenbach, M. A., \& Leventhal, H. (1996). The common-sense model of illness representation: Theoretical and practical considerations. Journal of Social Distress and the Homeless, 5(1), 11-38. https://doi. org/10.1007/Bf02090456.

Figueiras, M. J., \& Weinman, J. (2003). Do similar patient and spouse perceptions of myocardial infarction predict recovery? Psychology \& Health, 18(2), 201-216.

Finkel, R. S., Mercuri, E., Meyer, O. H., Simonds, A. K., Schroth, M. K., Graham, R. J., Kirschner, J., Iannaccone, S. T., Crawford, T. O., Woods, S., Muntoni, F., Wirth, B., Montes, J., Main, M., Mazzone, E. S., Vitale, M., Snyder, B., Quijano-Roy, S., Bertini, E., Davis, R. H., Qian, Y., Sejersen, T., \& SMA Care group. (2018). Diagnosis and management of spinal muscular atrophy: Part 2: Pulmonary and acute care; medications, supplements and immunizations; other organ systems; and ethics. Neuromusculular Disorders, 28(3), 197-207. https://doi.org/10.1016/j.nmd.2017.11.004.

Fischer, M. J., Asselman, F. L., Kruitwagen-van Reenen, E. T., Verhoef, M., Wadman, R. I., Visser-Meily, J. M. A., van der Pol, W. L., \& Schröder, C. D. (2019). Psychological well-being in adults with spinal muscular atrophy: The contribution of participation and psychological needs. Disability and Rehabilitation., 1-9. https://doi.org/10.1080/09638288.2018.1555864.

Giannousi, Z., Karademas, E. C., \& Dimitraki, G. (2016). Illness representations and psychological adjustment of Greek couples dealing with a recently-diagnosed cancer: Dyadic, interaction and perception-dissimilarity effects. Journal of Behavioral Medicine, 39(1), 85-93. https://doi.org/10.1007/s10865-015-9664-z.

Graham, C. D., Rose, M. R., Hankins, M., Chalder, T., \& Weinman, J. (2013). Separating emotions from consequences in muscle disease: Comparing beneficial and unhelpful illness schemata to inform intervention development. Journal of Psychosomatic Research, 74(4), 320-326. https://doi.org/10.1016/j. jpsychores.2012.09.012.

Graham, C. D., Weinman, J., Sadjadi, R., Chalder, T., Petty, R., Hanna, M. G., Turner, C., Parton, M., Maddison, P., Radunovic, A., Longman, C., Robb, Y., Bushby, K., Hilton-Jones, D., \& Rose, M. R. (2014). A multicentre postal survey investigating the contribution of illness perceptions, coping and optimism to quality of life and mood in adults with muscle disease. Clinical Rehabilitation, 28(5), 508519. https://doi.org/10.1177/0269215513511340. 
Hagger, M. S., \& Orbell, S. (2003). A meta-analytic review of the common-sense model of illness representations. Psychology \& Health, 18(2), 141-184.

Hagger, M. S., Koch, S., Chatzisarantis, N. L. D., \& Orbell, S. (2017). The common sense model of selfregulation: Meta-analysis and test of a process model. Psychological Bulletin, 143(11), 1117-1154. https://doi.org/10.1037/bul0000118.

Heijmans, M., de Ridder, D., \& Bensing, J. (1999). Dissimilarity in patients' and spouses' representations of chronic illness: Exploration of relations to patient adaptation. Psychology \& Health, 14(3), 451-466.

Iannaccone, S. T., Hynan, L. S., Morton, A., Buchanan, R., Limbers, C. A., Varni, J. W., \& AmSMART Group. (2009). The PedsQL (TM) in pediatric patients with spinal muscular atrophy: Feasibility, reliability, and validity of the pediatric quality of life inventory (TM) generic Core scales and neuromuscular module. Neuromuscular Disorders, 19(12), 805-812. https://doi.org/10.1016/j.nmd.2009.09.009.

Karademas, E. C., Zarogiannos, A., \& Karamvakalis, N. (2010). Cardiac patient-spouse dissimilarities in illness perception: Associations with patient self-rated health and coping strategies. Psychology \& Health, 25(4), 451-463. https://doi.org/10.1080/08870440802652089.

Klug, C., Schreiber-Katz, O., Thiele, S., Schorling, E., Zowe, J., Reilich, P., Walter, M. C., \& Nagels, K. H. (2016). Disease burden of spinal muscular atrophy in Germany. Orphanet Journal of Rare Diseases, 11(1), 58. https://doi.org/10.1186/s13023-016-0424-0.

Kolb, S. J., \& Kissel, J. T. (2015). Spinal muscular atrophy. Neurologic Clinics, 33(4), 831-846. https://doi. org/10.1016/j.ncl.2015.07.004.

Kruitwagen-Van Reenen, E. T. H., Wadman, R. I., Visser-Meily, J. M., van den Berg, L. H., Schröder, C., \& van der Pol, W. L. (2016). Correlates of health related quality of life in adult patients with spinal muscular atrophy. Muscle \& Nerve, 54(5), 850-855. https://doi.org/10.1002/mus.25148.

Leventhal, H., Meyer, D., \& Nerenz, D. (1980). The common sense representation of illness danger. In S. Rachman (Ed.), Contributions to medical psychology (Vol. 2, pp. 7-30). New York: Pergamon.

Leventhal, H., Diefenbach, M., \& Leventhal, E. A. (1992). Illness cognition: Using common sense to understand treatment adherence and affect cognition interactions. Cognitive Therapy and Research, 16(2), 143-163.

Leventhal, H., Leventhal, E. A., \& Contrada, R. J. (1998). Self-regulation, health, and behavior: A perceptualcognitive approach. Psychology \& Health, 13(4), 717-733. https://doi.org/10.1080/08870449808407425.

Leventhal, H., Brissette, I., \& Leventhal, E. A. (2003). The common-sense model of self-regulation of health and illness. In L. D. Cameron \& H. Leventhal (Eds.), The self-regulation of health and illness behaviour (pp. 42-65). New York: Routledge.

Rajmil, L., Lopez, A. R., Lopez-Aguila, S., \& Alonso, J. (2013). Parent-child agreement on health-related quality of life (HRQOL): A longitudinal study. Health and Quality of Life Outcomes, 11. https://doi. org/10.1186/1477-7525-11-101.

Ravens-Sieberer, U., Gosch, A., Rajmil, L., Erhart, M., Bruil, J., Duer, W., Auquier, P., Power, M., Abel, T., Czemy, L., Mazur, J., Czimbalmos, A., Tountas, Y., Hagquist, C., Kilroe, J., \& KIDSCREEN Group, E. (2005). KIDSCREEN-52 quality-of-life measure for children and adolescents. Expert Review of Pharmacoeconomics and Outcomes Research, 5(3), 353-364. https://doi.org/10.1586/14737167.5.3.353.

Ravens-Sieberer, U., Herdman, M., Devine, J., Otto, C., Bullinger, M., Rose, M., \& Klasen, F. (2014). The European KIDSCREEN approach to measure quality of life and well-being in children: Development, current application, and future advances. Quality of Life Research, 23(3), 791-803. https://doi. org/10.1007/s11136-013-0428-3.

Richardson, A. E., Morton, R., \& Broadbent, E. (2015). Caregivers' illness perceptions contribute to quality of life in head and neck Cancer patients at diagnosis. Journal of Psychosocial Oncology, 33(4), 414-432. https://doi.org/10.1080/07347332.2015.1046011.

Richardson, A. E., Morton, R. P., \& Broadbent, E. A. (2016a). Changes over time in head and neck cancer patients' and caregivers' illness perceptions and relationships with quality of life. Psychology \& Health, 31(10), 1203-1219. https://doi.org/10.1080/08870446.2016.1203686.

Richardson, E. M., Schüz, N., Sanderson, K., Scott, J. L., \& Schüz, B. (2016b). Illness representations, coping, and illness outcomes in people with cancer: A systematic review and meta-analysis. Psycho-Oncology, 26(6), 724-737. https://doi.org/10.1002/pon.4213.

Ringlever, L., Otten, R., van Schayck, O. C., \& Engels, R. C. (2012). The role of maternal illness perceptions in perceived asthma symptoms in school-aged children. Journal of Asthma, 49(10), 1030-1036. https://doi.org/10.3109/02770903.2012.726305.

Rizou, I., De Gucht, V., Papavasiliou, A., \& Maes, S. (2015). Illness perceptions determine psychological distress and quality of life in youngsters with epilepsy. Epilepsy \& Behaviour, 46, 144-150. https://doi. org/10.1016/j.yebeh.2015.03.022. 
Rizou, I., De Gucht, V., Papavasiliou, A., \& Maes, S. (2016). The contribution of illness perceptions to fatigue and sleep problems in youngsters with epilepsy. European Journal of Paediatric Neurology, 20(1), 9399. https://doi.org/10.1016/j.ejpn.2015.10.001.

Rose, M. R., Sadjadi, R., Weinman, J., Akhtar, T., Pandya, S., Kissel, J. T., Jackson, C. E., \& the Muscle Study Group. (2012). Role of disease severity, illness perceptions, and mood on quality of life in muscle disease. Muscle \& Nerve, 46(3), 351-359. https://doi.org/10.1002/mus.23320.

Sonney, J. T., \& Insel, K. C. (2016). Reformulating the common sense model of self-regulation: Toward parent-child shared regulation. Nursing Science Quarterly, 29(2), 154-159. https://doi.org/10.1177 /0894318416630091.

Sonney, J. T., Gerald, L. B., \& Insel, K. C. (2016). Parent and child asthma illness representations: A systematic review. Journal of Asthma, 53(5), 510-516. https://doi.org/10.3109/02770903.2015.1116088.

Sonney, J., Insel, K. C., Segrin, C., Gerald, L. B., \& Ki Moore, I. M. (2017). Association of asthma illness representations and reported controller medication adherence among school-aged children and their parents. Journal of Pediatric Health Care, 31(6), 703-712. https://doi.org/10.1016/j.pedhc.2017.06.002.

Szentes, A., Kokonyei, G., Bekesi, A., Bokretas, I., \& Torok, S. (2018). Differences in illness perception between children with cancer and other chronic diseases and their parents. Clinical Child Psychology and Psychiatry, 23(3), 365-380. https://doi.org/10.1177/1359104517731899.

Twiddy, M., House, A., \& Jones, F. (2012). The association between discrepancy in illness representations on distress in stroke patients and carers. Journal of Psychosomatic Research, 72(3), 220-225. https://doi. org/10.1016/j.jpsychores.2011.12.004.

Vanbelle, S. (2016). A new interpretation of the weighted kappa coefficients. Psychometrika, 81(2), 399-410. https://doi.org/10.1007/s11336-014-9439-4.

Weinman, J., Heijmans, M., \& Figueras, M. J. (2003). Carer perceptions of chronic illness. In L. D. Cameron \& H. Leventhal (Eds.), The self-regulation of health and illness behaviour (pp. 207-219). New York: Routledge.

Publisher's Note Springer Nature remains neutral with regard to jurisdictional claims in published maps and institutional affiliations. 